\title{
To Compare and Contrast Expressions of Sadness and Happiness in English and Arabic
}

\author{
Sawsan M.A. Ahmed ${ }^{1}$ \\ ${ }^{1}$ Taif University, Kingdom of Saudi Arabia \\ Correspondence: Sawsan M.A. Ahmed, Taif University, Kingdom of Saudi Arabia \\ Received: February 19, 2016 \\ Accepted: March 1, 2016 \\ Online Published: March 2, 2016 \\ doi:10.5430/elr.v5n1p6 \\ URL: http://dx.doi.org/10.5430/elr.v5n1p6
}

\begin{abstract}
This paper sheds light into the similarities and differences between expressions related to sadness and happiness in English and Arabic and establish the commonality of conceptualization and understanding these emotions. The work of Kovecses and others is reviewed and a comparison is determined as far as the two emotions, sadness and happiness in applying some of the emotional mappings such as; sadness is DARKNESS, as AN ILLNESS, as AN OPPONENT, and happiness LIFTS YOU UP, HAPPINESS IS LIGHT among others between English and Arabic. A conclusion was reached that most emotions across the two cultures when it comes to metaphor mapping are similar among some minor differences.
\end{abstract}

Keywords: Sadness expressions in English and Arabic, Arabic expressions of sadness, Compare and contrast sadness expressions

\section{Introduction}

Sadness is defined by "The Oxford Dictionaries" Feeling or showing sorrow. Other words are grief (a stronger feeling, for example when someone has died) or depression (feeling sad for a long time). Some people think depression is a different emotion, whereas the same source defines happiness as feeling happy. Other words are glad, delighted. Metaphorical language is an indispensable part of human life, involving language, thought and action (Lakoff \& Johnson, 1980, Lakoff, 1998).

Such emotions are conceptualized by researchers as metaphors. The idea of metaphor is ancient. Aristotle made a first attempt to give a scientific account of metaphor. In the philosopher's view, metaphor is the transfer of the name of a thing to another thing were uses in language The Conceptual Metaphor Theory was shaped by Lakoff and Johnson in 1990 as a reason dissatisfaction with the role attributed to metaphor in the philosophical and linguistic theories. Linguists have found proof that convinced them that metaphor is present in language and thought; hence, it may be central to human cognition. Such observation has lead to evidence that could not be accounted for in the traditional theories. Thereby, the need to create a new theory that would satisfy and explain the issue became necessary. Lakoff and Johnson's approach to metaphor can be characterized as innovatory in the sense that it builds a new foundation by considering metaphors as a thought and only as a theme of language. This conception of the topic has changed the status of metaphor considerably so that today it is studied not only by linguists but also by literature specialists and researchers from a wide range of disciplines such as, philosophy, and psychology.

\section{The Source Domain and Target}

The conceptual metaphor is a set of systematic correspondences or mappings between what is called a source domain and a target. The source domain is associated with some tangible physical experiences. Therefore, it is more concrete than the target domain. As an example, the source domain of ENEMY is more concrete and less complex than the target domain of ENEMY in the SADNESS IS AN ENEMY metaphor. It is a conceptual domain that researchers utilize in order to understand the target. However not all bodily experiences give rise to "emotion metaphors" The scope of "emotion metaphors" has been discussed by (Kövecses, 2000) Where a clear understanding of "how people comprehend emotion concepts in a unique way" is made (p. 35-50), Selected metaphor mapping taken from the works of Kövecses and Lakoff and are used to compare and contrast metaphor expressions in English and Arabic. These metaphors are; SADNESS IS A FLUID IN A CONTAINER, SADNESS IS DARK AND HAPPINESS IS LIGHT, SADNESS IS AN OPPONENT, SADNESS IS DOWN and HAPPINESS IS UP, SADNESS IS AN OTMOSPHERE, SADNESS IS NATURAL FORCE, SADNESS IS INSANITY, SADNESS IS AN ILLNESS. 


\section{Linguistic Applications}

John Searle approaches metaphor through the framework of The Speech Act Theory (Searle, 1993). According Searle each statement encompasses of two types of meaning: 1. sentence meaning 2. Speaker's utterance meaning.

Sentence meaning is compositional: sentences derive their meanings from the meanings of their constituent elements and the rules that are employed to conjoin them. Moreover, sentence meaning, as semantics linguists such as (Kearns, 2004) calls are truth-conditional: a sentence is true if and only if its truth conditions are satisfied. Speaker's utterance meaning is the meaning that the speaker wishes to communicate to the hearer. Metaphor is an attribute of speaker's utterance meaning and as such is a deviation from the literal meaning. (Searle, 1993, p. 84).

\section{Data Collection and Methodology}

The present study adopts the conceptual metaphor theory (Lakoff \& Johnson, 1980) to compare and contrast emotional metaphorical expressions in English and Arabic. As a first step, a number of metaphorical expressions used in describing sadness and happiness in both languages were collected. The English emotive metaphorical expressions were gathered mainly from the works of Lakoff and Kövecses (Lakoff, 1980; Lakoff \& Kovecses, 1987; Kovecses, 1991) and from The Oxford Dictionary of Idioms and The Oxford Dictionary of Proverbs. Also the Internet and The British National Corpus, and Encyclopedia are used to verify and collect the data. Some of the Arabic metaphors are taken from the "Alshamila library" and from old sayings found on the internet taken from old folklore.

\section{Practical Implications of the Study}

The expressions generated by the study can be used in teaching a course of Cognitive Linguistics (comparative studies) The paper is also valuable for Preparing comparative metaphor dictionaries in Arabic. The research is largely inspired by the deeply felt lack of documented metaphors conceptualization and metaphor comparisons. It may also prove to be of interest to journalists as well as for specialists working within the field of literary, cultural studies and ethnography.

\subsection{Sadness as a Concept}

The concept of sadness has a long history of recognition as an emotion experienced as a result of loss. Lewis, Haviland-Jones and Barrett (2008) claim that "the feeling of sadness involves sensations of loss" (p. 377). Other words associated with sadness are grief, and depression.

\subsection{Happiness as a Concept}

In English, Happiness is defined as "The state of being happy" Other words are ecstatic, overjoyed, thrilled. Lakoff and Johnson (1980) described happiness as an emotion that is characterized by a high energy activity such as dancing, singing or jumping (p. 15).

\subsection{Sadness and Happiness as A FLUID IN A CONTAINER}

The idea of sadness as a content metaphor is indicated by Kovecses (1990). He introduced the idea that sadness is an emotion that can be conceptualized as a fluid and encompassed in a container. Containers in describing sadness are body parts such as eyes, heart and the soul. First, in the case of sadness is a container, Arabic includes many expressions to illustrate sadness as a container; such as 'ت مـ لـكها ال حزن ' 'Sadness owned her' 'Sadness contained and gripped her' and secondly, Sadness as a content; there are a number of expressions that indicate such a thought as sadness is a fluid in a container 'ملأ ع يـ بهال حزن' 'Sadness has filled her eyes' and 'ملأ لـ حزن ق لـ به 'Sadness has filled his heart'. As in the case of happiness in Arabic, it is also conceptualized as FLUID IN CONTAINER as used in an expression "Happiness filled her heart'.ملأ الفرح قلبها'

\subsection{Sadness is DARK and Happiness is LIGHT}

In the case of sadness is dark, it is believed that the color black is a good representative of sadness. Therefore, people who are sad prefer dark to light places (Kovecses, 2000). In an experience conducted in 2010 on people to choose a color to represent their mood when shown an array of colors; sad people picked darker shades from black to different shades of gray; whereas happier people chose brighter colors. In Arabic the state of being happy is marked by wearing colorful clothes where as people that are in morning wear black. Therefore, black is the common color of sadness. According to data, dark color as a metaphor is common in English and Arabic and the concept is shared in the two cultures. English expressions, such as 'Someone is in a dark mood', 'The situation looks bleak' and 'He lives in a gloomy city'. These are clear representation of the loss of hope which is a leading cause for sadness. Happiness in English is illustrated by using expressions like 'The news brightened up the whole day for me' 'The girl looks 
radiant in this picture', 'Her eyes shone with delight' and 'The future looks bright'. Happiness is associated with light as in HAPPINESS IS LIGHT 'her eyes brightened up'. In Arabic the concept is shared and used in expressions like ' إ 'اء الـ فرح هلوجه 'happiness lit her face'. HAPPINESS IS LIGHT is also used in expressions like: 'Her eyes were brightened up with joy'.

\section{Color as a Metaphor}

Colors are a big part of culture; they do not only express the colors themselves, but also are mixed and used with the cultural characteristics of each nation. The relation between culture and language renders great effects on connotations of color words (Wang, 2007). In English, being sad is represented in the color blue. When someone is sad, they use expressions such as 'Feeling blue', 'Get the blues', In Arabic however; such an expression does not exist. Therefore misunderstandings are created between speakers of Arabic and speakers of English and are common in the case of learning English as a foreign language. These kinds of metaphorical expression must be rendered into metaphorical meaning to avoid misunderstanding. They are different because of the absence of blue as a color of being sad. Sadness is indicated by the color black. Being happy in English is represented by bright colors. Speakers use expressions like 'His future looks rosy' ' she looks at life through rosy colored spectacles'.

\subsection{Sadness is AN OPPONENT}

Another concept personified by sadness is the embodiment of sadness as an enemy whereas happiness is represented as a friend. Such a personification is presented by data in English and Arabic. In the following expressions in English, they reveal this kind of metaphor such as; 'She was overcome by sadness' In these examples, sadness is represented as an opponent to fight. Either it will overcome you or you will overcome it. Similarly, Arabic speakers use the opponent metaphor in describing someone's sadness. In English sadness can attack the person and score victory upon him/her. Similarly in Arabic sadness is considered an enemy that could cause pain and inflict harm on the person. كسر الحزن ضهرها" 'Sadness has broken her back'. As far as happiness, it is recognized as a positive emotion both in اضحك تضحك لك 'Arabic and in English. In Arabic, Laughter is a main character associated with being happy. It says: 'الدنيا 'when you laugh, the world laughs with you'. Here happiness is seen as an ally that can reward you for being happy.

\subsection{Sadness is DOWN and Happiness is HIGH}

Lakoff \& Johnson (1980) introduced the conceptual metaphors representing happiness as moving in an UPWARD direction. In such metaphors, happiness is associated with being in an elevated place off the ground. A Conceptual metaphor is common in both Arabic and English. Sadness is imagined as a burden imposed on the sad people as in SADNESS IS DOWN. It weighs people down as happiness LIFT PEOPLE UP The English expression 'He struggled under a heavy burden of sadness" exemplify sadness as a burden that makes people stagger under. In Arabic similar

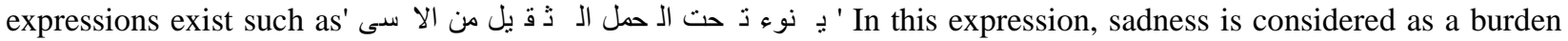
that people have to endure. In English expressions like 'down in the dumps', 'My heart sank' and 'He was in the depths of despair'. Depression caused by sadness is also exemplified by downward spiral motion. Happiness expressions in English also show the lifting action like the expression 'on cloud nine'; 'The news really lifted her spirit' 'Things are looking up finally'. Similarly in Arabic there exists an expression such as 'طار-طارت من الفرح' 'S/He flew because s/he was happy'. Happiness in English has been recognized in major metaphors such as: HAPPINESS IS UP 'I'm feeling up', 'I'm walking on air'.

\subsection{Sadness and Happiness is AN ATMOSPHERE}

Sadness is an atmosphere is common in both Arabic and English. It is identified by Barcelona (1986). The research data illustrates the ATMOSHERE metaphor as an environment in which people can feel different emotions. The sad atmosphere is mentioned as an example that implies a 'sea or ocean of grief that someone can drown in' English metaphorical expression. Happiness expressions vary in the two cultures. Sometimes what is considered a happy atmosphere in the western world is considered a somber atmosphere in the Arab world. For instant, a wedding is considered a happy occasion in the western world, whereas in some Arab traditional cultures it is considered a somber occasion. Other Arabic expressions that indicated the spreading of happiness around and making it as an atmosphere such as; تنشر الفرح من حولها' 'She spreads the joy around'.

\subsection{Sadness and Happiness as A NATURAL FORCE}

In this metaphor, sadness is depicted as a destructive natural force. Kovecses used a number of verbs to describe such a metaphor like 'seized by emotion', 'struggled with emotion', and 'gripped by emotion' and 'overcome by emotion' In Arabic sadness is depicted as some natural phenomena as well. In an Arabic metaphorical example such as المشاعر 
"'الجياشة' 'overcome by emotion' also depicts both sadness and happiness as a force that can overcome a person. Happiness is also depicted as a force in Arabic that can 'blow the person away 'يطيرك من الفرح'.

\subsection{Sadness is INSANITY}

As Kovecses (2000) states that the intense emotion is a state of 'ultimate lack of control'(74). In the insanity metaphor a normal person becomes insane as a result of the intense psychological force. Consequently, the irrationality resulting from intense emotions like sadness causes a mild form of insanity. Kovecses represented the idea by metaphor mapping where a normal person loses control under intense psychological force. That can cause a normal person to become insane and irrational. Therefore, it is more precise to state that the effect of an intense emotion is insanity'(ibid). Irrational behavior has been demonstrated by people who suffer from extreme sadness. In Arabic, losing control of the senses can cause people to do what is called " شق الج يب " which is 'tearing of one's clothes' Furthermore, Kovecses (1990) demonstrated that 'strong emotions are madness'. It is true in the case of intense sadness in a sad person, because of the lack of rational thinking. Happiness is also depicted in Arabic as a force that drives the person to madness as the common expression for happiness 'بـ 'ب ني 'it drives you crazy' but the expression occurs in casual spoken Arabic.

\subsection{Sadness is AN ILLNESS and Happiness is HEALTH}

According to Kovecses (2000) emotions can be judged to be positive or negative. Emotions which are viewed as negative are in part understood as an illness (44). Kovecses presented an emotional mapping for sadness and portrayed it as an illness. Traditionally, in English the metaphors are very similar to Arabic as many metaphorical expressions in English presented sadness as an illness. English expressions, 'Time heals all sorrows', and 'She was heart-sick' are the examples of the illness metaphor for sadness. Similarly, Arabic employs the same metaphor in conceptualizing sadness. In the Koran Islam's holy book Jacob lost his eye sight for the loss of his son 'و 'و 'Oيضت عيناه نح نز نول 'Oh, my sorrow over Joseph, 'and his eyes became white from grief' (12: 84). The sign of happiness is represented in Jacob's eyesight was restored as the news of his son's safety reached him. 'فارتد بصير ' and he returned [once again] seeing' (12: 96).

\section{Conclusion}

The majority of the metaphors found in this paper portray sadness as an emotion that is initiated by loss through death, divorce, war, etc. In some metaphors, sadness is characterized as AN OPPONENT, as A NATURAL FORCE and generally as a force to be reckoned with. As for the happiness metaphors, happiness is associated with metaphors such as HAPPINESS LIFTS YOU UP. Moreover, it gives proof that some conceptual metaphors related to sadness and happiness used today and exist across the two cultures are somewhat similar. It was also found that English and Arabic speakers share common grounds and apply most of the metaphors of sadness and happiness. In the metaphors of the emotions under consideration in this paper, it was also observed that the metaphors are almost unified except for minor differences. To conclude, the universality of depicting the two opposing emotions sadness and happiness is visible throughout the two cultures.

It has to be asserted however, that much is not yet known about the pragmatic basis of emotion metaphors. Researchers are only scratching the surface to discover the commonality of metaphor mapping across cultures. Nevertheless, some important factors concerning the issue have already been established. Correlation in experience seems to be one of the main reasons to explain certain metaphors representing a particular emotion. By looking at the similarities and differences, it can be seen that there are more similarities than differences both in the sadness and happiness metaphors between English and Arabic.

\section{References}

Barcelona, A. (1986). On the concept of depression in American English: A Cognitive Approach. Revista Canaria de Estudios Ingleses, 12, 7-33.

Kearn, K. (2004). Semantics. London: Palgrave.

Kövecses, Z. (1990). Emotion Concepts. New York: Springer Verlag.

Kövecses, Z. (1991). Happiness: A Definitional Effort. Metaphor and Symbolic Activity, 6, 29-46.

Kövecses, Z. (2000). Metaphor and Emotion: Language, Culture, and Body in Human Feeling. New York: Cambridge University Press.

Lakoff, G. \& Johnson, M. (1980). Metaphors We Live By. Chicago: University of Chicago Press.

Lakoff, G. (1987). Women, Fire and Dangerous Things: What Categories Reveal about the Mind. Chicago: University of Chicago Press. 
Lakoff, G. \& Turner, M. (1989). More than Cool Reason: A Field Guide to Poetic Metaphor. Chicago: University of Chicago Press.

Lakoff, G. (1993). Contemporary Theory of Metaphor. In: A. Ortony (ed.), Metaphor and Thought, 2 nd ed. Cambridge: Cambridge University Press, 202-251.

Lakoff, G. \& Johnson, M. (1999). Philosophy in the Flesh: The Embodied Mind and its Challenge to Western Thought. New York: Basic Books.

Lewis, M., Haviland-Jones, J. M., \& Barrett, L. F. (2008). The handbook of emotion, 3th Edition. New York: Guilford.

Niemeier, S. (2003). Straight from the Heart: Metonymic and Metaphorical Explorations. In: A. Barcelona (ed.), Metaphor and Metonymy at the Crossroads: A Cognitive Perspective. Berlin: Mouton de Gruyter, 195-21

Searle, J.R. (1993). Metaphor. In: A. Ortony (ed.), Metaphor and Thought, 2nd ed. Cambridge: Cambridge University Press, 83-111.

The Holly Koran: https://simple.wikipedia.org/wiki/List_of_emotions(Visited 14.4 2014).

http://classics.mit.edu/Aristotle/poetics.3.3.html.(Visited: 01.04.14).

http://shamela.ws/

http://www.livescience.com/6084-colors-describe-happiness-depression.html (Visited 14.4 2014). 